\title{
Closure of a giant anterior sacral meningocele with an omental flap in a patient with Marfan syndrome: case report
}

\author{
Gabriella M. Paisan, BA, ${ }^{1}$ Kenneth M. Crandall, MD, ${ }^{2}$ Stephanie Chen, MD, ${ }^{2}$ S. Shelby Burks, MD, ${ }^{2}$ \\ Laurence R. Sands, MD, ${ }^{3}$ and Allan D. Levi, MD, PhD²
}

'Department of Neurosurgery, University of Virginia, Charlottesville, Virginia; ${ }^{2}$ Department of Neurological Surgery and The Miami Project to Cure Paralysis, University of Miami Miller School of Medicine, Miami, Florida; and ${ }^{3}$ Department of General Surgery, University of Miami Miller School of Medicine, Miami, Florida

\begin{abstract}
Anterior sacral meningoceles (ASMs) are rare lesions often associated with connective tissue disorders. These lesions are typically treated posteriorly via closure of the dural stalk. However, given their insidious nature, ASMs can be quite large on presentation, and this approach may not provide adequate decompression. In this case report, the authors describe the successful treatment of a large ASM through drainage and watertight closure of the cyst with an omental flap.

A 43-year-old woman with a history of Marfan syndrome and a large ASM was referred for neurosurgical intervention. The ASM was filling the pelvic cavity and causing severe compression of the bladder. The patient underwent surgical decompression of the cyst through an anterior transabdominal approach and closure of the fistulous tract with a pedicled omental flap. This is the first reported case of successful closure of an ASM with an omental flap. At the 6-month followup, the ASM had not recurred on imaging and the patient's symptoms had resolved.

Anterior sacral meningoceles are rare lesions that often require neurosurgical intervention. Although most can be treated posteriorly, large ASMs compressing the abdominal or pelvic organs may require a transabdominal approach. Moreover, ASMs with wide dural stalks may benefit from closure with an omental flap.
\end{abstract}

https://thejns.org/doi/abs/10.3171/2018.1.SPINE171303

KEYWORDS meningocele; Marfan syndrome; anterior surgery; Tarlov cyst; surgical technique

A NTERIOR sacral meningoceles (ASMs) are rare clinical entities that can occur sporadically or in association with connective tissue disorders such as Marfan syndrome or Loeys-Dietz syndrome. 5,6,18,21,22,29 They are thought to arise from congenital bony defects in the anterior sacrum with subsequent ballooning of the dura mater through the defect, which can become large over time, causing a number of clinical presentations from compression of structures in the abdomen or pelvis. ${ }^{8,21,22}$ Although they can be conservatively observed, ASMs are typically treated surgically through a posterior approach to decompress the meningocele and close the dural stalk from which it originates.

Here we present the case of a 43-year-old woman with a large ASM causing progressive abdominal pain and urinary incontinence and frequency secondary to bladder compression from the cyst. We also describe a novel tech- nique for successful management of the ASM-closure of the meningocele with the use of an omental flap-which has not been previously reported in the literature.

\section{Case Report}

History and Examination

A 43-year-old woman with a history of Marfan syndrome and a known large ASM was referred for neurosurgical intervention due to progressive symptoms of abdominal pain, increasing abdominal girth, and stress urinary incontinence secondary to bladder compression from the meningocele. She originally presented 2 years earlier with symptoms of low-back pain and minor abdominal pressure, at which time MRI revealed the cyst, which was deemed nonoperative at the time. At the time of presentation to our clinic, MRI revealed that the ASM had grown 

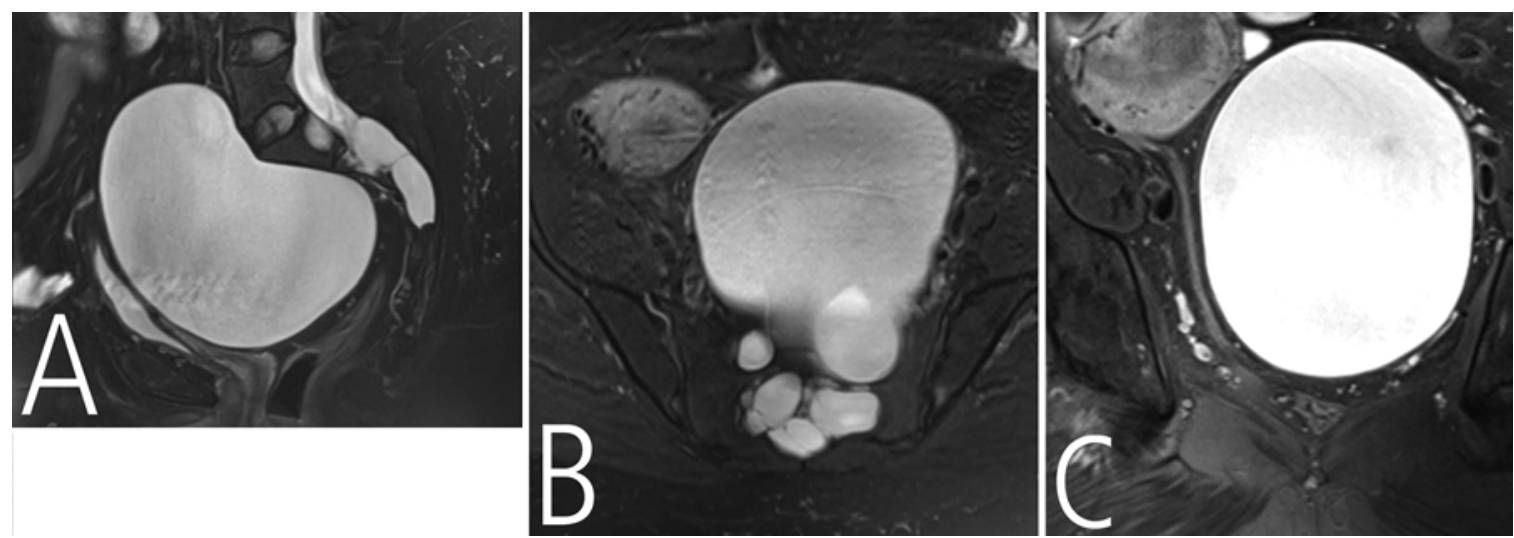

FIG. 1. Sagittal (A), axial (B), and coronal (C) T2-weighted MR images of the pelvis showing a large ASM filling the pelvic cavity. A wide dural stalk could be seen arising from the left S-2 region (A), and the cyst was associated with multiple Tarlov cysts posteriorly (B).

significantly, measuring $13.5 \times 11.4 \times 12.4 \mathrm{~cm}$. The ASM emanated from the left S-2 anterior sacral foramen, extending rostrally to the L4-5 interspace, filling the pelvic cavity, extending anteriorly to the anterior abdominal wall, causing severe compression of the bladder. The cyst was associated with multiple Tarlov cysts posteriorly (Fig. 1). Motor testing revealed full strength bilaterally in the lower extremities, and sensation to pinprick and light touch was intact. She had negative straight leg raise tests but positive bilateral Patrick's tests.

\section{Operation}

The patient elected to undergo surgical treatment of the meningocele. Prior to surgery, a lumbar drain was placed to help decompress the thecal sac and reduce cerebrospinal fluid (CSF) pressures in order to increase the chance of a successful repair. With the assistance of a colorectal surgeon, an anterior transperitoneal approach was utilized to access the meningocele. Adherent bowel was freed, and the ovaries, uterus, ureters, and bladder were identified and carefully separated from the meningocele wall (Fig. 2A). The dural wall was then incised and several liters of CSF were drained from the ASM. Within the sac, a large bony defect in the anterolateral sacrum and several ventral Tarlov cysts were identified (Fig. 2B). Fluorescein dye was injected through the lumbar drain and could be seen subsequently draining from a small hole deep within the ASM sac (Fig. 2C). Next, an omental flap was created and tacked adjacent to the dural defect in the anterior sacrum, filling the ASM sac (Fig. 2D). The ASM sac was then closed around the omentum in a watertight fashion, thus obliterating the ASM.

\section{Postoperative Course}

Postoperatively, the patient was placed on flat bed rest with the lumbar drain open and an abdominal binder for 6 days, at which point she underwent CT myelography for evaluation of the meningocele repair. The myelogram showed no leakage of CSF through the anterior sacral defect, and the lumbar drain was subsequently removed. At her 1-week and 3-month follow-up appointments, the patient's abdominal pain and bladder symptoms had com- pletely resolved. The 3-month MRI follow-up demonstrated the omental flap in place and resolution of the meningocele (Fig. 3). At her 6-month follow-up visit, the patient continued to do well clinically, although she developed a small incisional hernia. A pelvic CT scan obtained at this time demonstrated no evidence of ASM recurrence.

\section{Discussion}

Marfan syndrome is a genetic disorder of the connective tissue and can affect multiple organ systems with symptoms frequently presenting in the pediatric age group. It is an autosomal dominant-inherited connective tissue disorder caused by a fibrillin-1 gene mutation. . $^{16,26,33}$ Twenty-five percent of the time, the condition arises from a de novo genetic mutation, and symptom severity is based on variable expressivity of the gene. Clinical diagnosis is often based on the Ghent criteria. ${ }^{14}$

Dural ectasias are well-recognized sequelae of Marfan syndrome. They are formed from a weakening or expansion of the dura, which can slowly enlarge with CSF pulsations and eventually erode through the vertebral body. ${ }^{15,25}$ It is thought that ASMs in patients with Marfan syndrome occur when ectatic dura expands through bony defects in the sacrum, leading to subsequent herniation of meninges and occasionally neural contents, although the molecular basis for this relationship has not been described.

Although the prevalence of ASM in Marfan syndrome is unknown, dural ectasias are known to occur with high frequency (up to 89\%) in this population. ${ }^{16,26}$ Moreover, ASMs have been reported to occur four times as often in females than in males; ${ }^{32}$ however, this is likely confounded by the fact that women are significantly more likely to undergo pelvic imaging for unrelated reasons. ASMs can also occur sporadically, as part of an inherited defect of the sacrococcygeal spine, as in Currarino syndrome, or with other connective tissue disorders such as LoeysDietz syndrome. ${ }^{5,8,12,26}$ ASMs in any of these populations are likely to remain asymptomatic until adulthood (mean age at presentation 20-30 years), but they can also rarely present as a presacral mass in a child. . $^{3,830}$

Generally, ASMs do not present until they have grown 

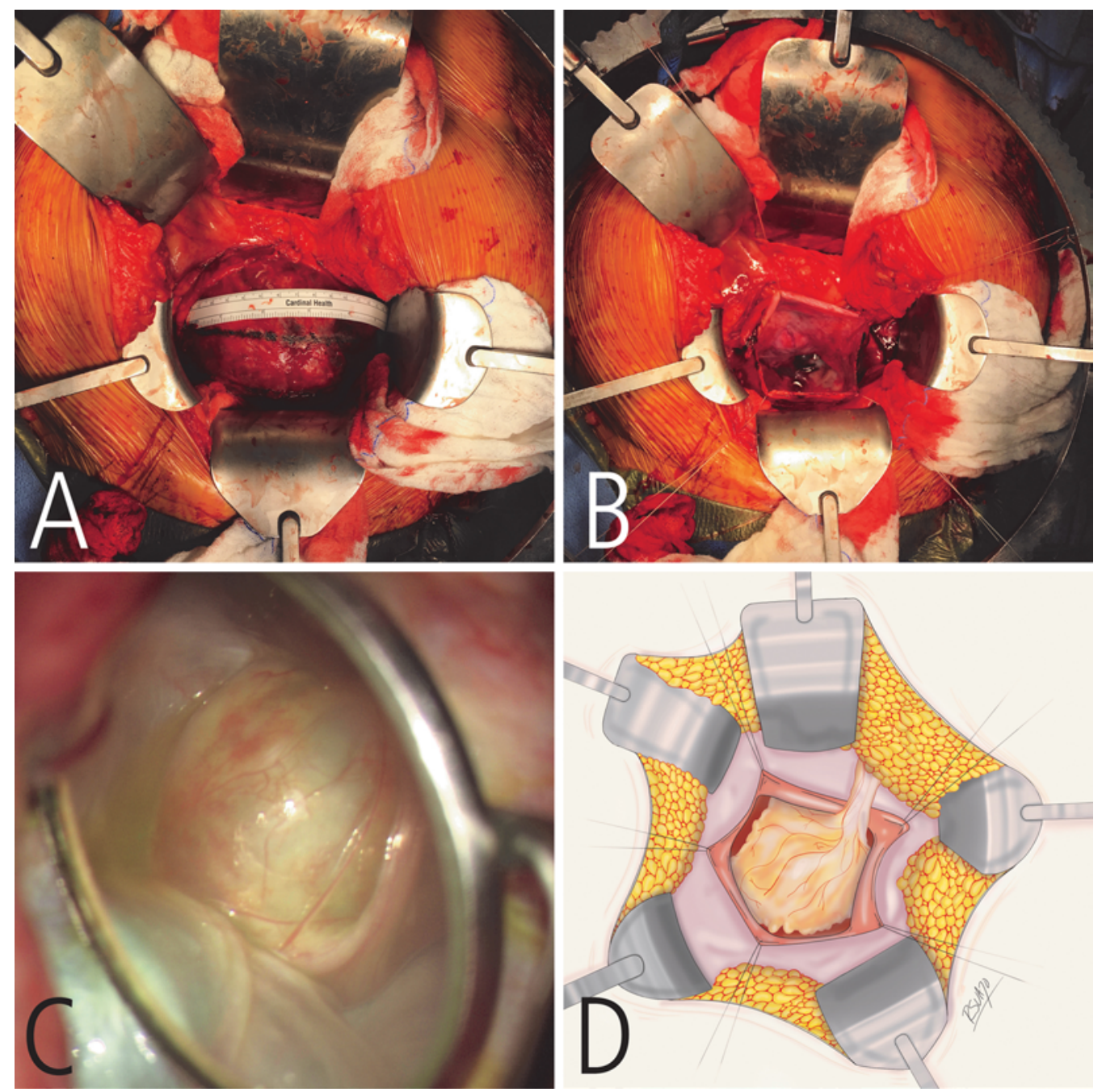

FIG. 2. A: Abdominal exposure of the ASM with a ruler for scale. Black horizontal line represents the cauterized area prior to incision of the ASM. B: After opening the meningocele and draining the fluid, the sacral promontory was visualized. C: Using a dental mirror to visualize the S-2 foramen, we saw a smaller Tarlov cyst with fluorescein leaking from a small dural defect. Small ventral nerve roots were visible inferolaterally. D: Illustration of omental flap freed and placed ventral to the sacrum to fill the prior CSF space created by the ASM. Illustration copyright Roberto Suazo. Published with permission.

to a considerable size and are able to exert pressure on pelvic and abdominal structures. The mass effect caused by the cyst can produce a wide range of symptoms including dysmenorrhea, urinary incontinence, low-back pain, lower extremity pain, pelvic pain, abdominal pain, and abdominal distension. ${ }^{21,22,24,29}$ Symptomatic lesions in children most often present as constipation. ${ }^{3,17}$ ASMs can also present with progressive neurological symptoms or low-pressure headaches, although this is less common. ${ }^{4,28,31}$ A rare but feared complication of ASM is spontaneous rupture of the cyst, leading to subsequent septic meningitis. This is particularly worrisome in pregnant women as the cyst has a higher likelihood of rupture during labor and delivery. ${ }^{10}$

As with any pelvic mass, pelvic ultrasound is the firstline imaging modality for ASMs. However, it can be difficult to delineate the origin and extent of the ASM using ultrasound alone, so further imaging is often needed.22 Gadolinium-enhanced MRI of the pelvis is the test of choice, although CT myelography and plain radiography can also be helpful. ${ }^{13,27}$ Because ASMs are occult lesions that can result in neurological morbidity from associated cord tethering or fistulous tract creation, it is recommended that all children of parents with a known history of ASM undergo screening with an anteroposterior lumbosacral radiograph. ${ }^{8}$ If the radiograph is negative but suspicion remains high based on a patient's symptoms, then MRI may be useful; otherwise, no further imaging is necessary in asymptomatic individuals. Additionally, no screening recommendations exist for patients with connective tissue disorders that predispose for ASMs.

Spontaneous regression of ASMs has not been reported in the literature. Hence, these lesions generally require surgical treatment regardless of their presentation. ${ }^{8}$ A number of surgical options have been described, including anterior transabdominal, posterior sagittal, or posterior transsacral approaches. ${ }^{1,15,30}$ In the past, transvaginal and transrectal aspirations were attempted, but these techniques have 


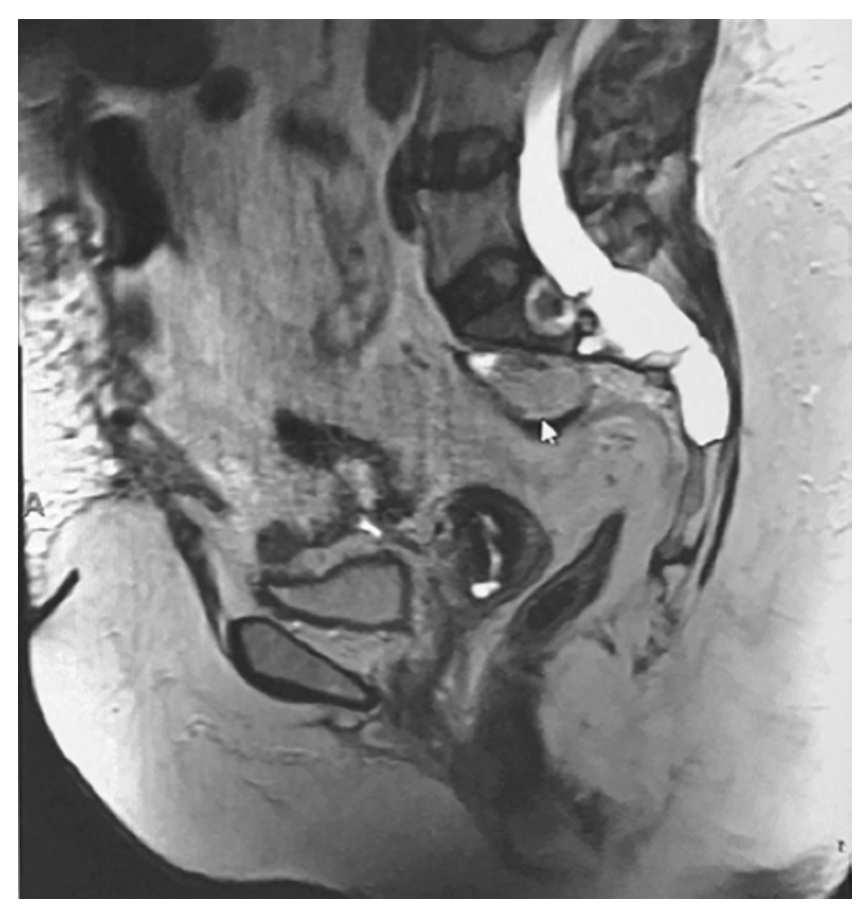

FIG. 3. Postoperative T2-weighted MR image of the lumbar and sacral spine obtained at 3-month follow-up, demonstrating resolution of the ventral ASM.

been abandoned because of unacceptably high risks of infection and cyst recurrence..$^{10}$ The posterior transsacral approach is most commonly described in the literature and is generally the preferred option. The aim of this approach is to identify and disconnect the fistula between the cyst and the CSF space, allowing the cyst to spontaneously resolve over time..$^{15,19,28}$ This is accomplished through a laminectomy at the level of the lesion, which also allows for the treatment of an associated tethered cord if present. The posterior sagittal approach accesses the meningocele stalk through a midline incision running from the sacrum through the anus. ${ }^{20}$ This approach allows for full visualization of the meningocele and any associated tumors and carries a very low risk of meningitis. ${ }^{15,19,28}$ However, given the required disruption of the anal sphincter, it is associated with a number of complications including anal stenosis. Thus, the approach is most useful in children with associated anorectal anomalies, which can also be corrected through this approach.

Patient and ASM characteristics must be carefully examined to determine the best approach for each individual. One major obstacle to the posterior approach is the amount of paraspinal soft tissue and bone removal required to reach the ASM. This approach becomes exceptionally difficult when attempted in obese patients as the surgeon must work in a deep wound, making identifying and maneuvering around vital structures difficult. The size of the lesion should also be considered since patients with very large ASMs causing symptoms from mass effect may not experience adequate relief from the posterior approach. In these cases, it is more beneficial to use an anterior transabdominal approach because the lesion can be entirely excised with this technique. In our patient, it was believed that because of the large size of the lesion, the patient's symptoms from mass effect of the cyst, and her obese body habitus, she warranted an anterior transabdominal approach for cyst decompression. Furthermore, the presence of multiple Tarlov cysts would make identification of the fistula challenging from a posterior approach.

The anterior approach, although useful for some patients with ASM, poses its own challenges. For example, it exposes abdominal and pelvic organs to the possibility of surgical trauma, which increases the risk of meningitis. ${ }^{7,13,27}$ This approach is also relatively unfamiliar to most neurosurgeons and often requires the assistance of a general surgeon in order to adequately expose the lesion. Another limitation of the approach is the relative difficulty in obtaining a watertight dural closure. However, our procedure ameliorated this difficulty with the use of an omental flap, essentially creating a large fat graft to provide reinforcement of the anterior cyst wall, which should prevent ASM recurrence.

To our knowledge, this is the first reported case of dural closure of an ASM with an omental flap. In our patient, the dural stalk connecting the ASM to the thecal sac was quite wide, and a watertight closure of the dura would not have been possible without the aid of the omental flap. Although few cases have involved the use of pedicled omental flaps to obtain dural closure of spinal wounds, those few have reported good outcomes with this technique. Among these are two cases of an omental flap used to close a thoracic dural tear and one case of an omental flap used to prevent CSF leakage after sacral malignancy resection. At the 1 year follow-up, the pedicled omental flaps were still viable and the patients had no recurrence of the CSF leak. ${ }^{11,23} \mathrm{Ad}-$ ditionally, the omentum contains a rich vasculature originating from the gastroepiploic system, which can help to prevent infection and increase the likelihood of flap survival., ${ }^{, 23}$ Also, because these vascular arcades are long and easily identified, the size and shape of the omental flap can be contoured to the patient's needs without disrupting its vascular supply. ${ }^{2}$

Although we describe a new method to successfully remove and close an ASM, we acknowledge that this is only a single case with limited (6 months) follow-up. However, we believe that this method presents an important alternative to the posterior approach for patients with large defects with wide dural stalks, for obese patients, and for those with symptoms from mass effect requiring decompression of the cyst.

\section{Conclusions}

Anterior sacral meningoceles are rare lesions generally requiring neurosurgical intervention through a variety of approaches. Although most ASMs should be treated posteriorly, large meningoceles compressing the abdominal or pelvic organs may require a transabdominal approach. For these lesions, particularly those with wide stalks, an omental flap may be useful in creating a watertight closure of the cyst.

\section{References}

1. Arnold PM, Teuber J: Marfan syndrome and symptomatic 
sacral cyst: report of two cases. J Spinal Cord Med 36:499503, 2013

2. Barrow DL, Nahai F, Tindall GT: The use of greater omentum vascularized free flaps for neurosurgical disorders requiring reconstruction. J Neurosurg 60:305-311, 1984

3. Bedi NK, Chadha R, Bagga D, Anand R, Mohta A: Anterior sacral meningocele: an uncommon cause of constipation in early childhood. Indian Pediatr 29:1157-1160, 1992

4. Bergeron E, Roux A, Demers J, Vanier LE, Moore L: A 40-year-old woman with cauda equina syndrome caused by rectothecal fistula arising from an anterior sacral meningocele. Neurosurgery 67:E1464-E1468, 2010

5. Chen CP: Syndromes, disorders and maternal risk factors associated with neural tube defects (II). Taiwan J Obstet Gynecol 47:10-17, 2008

6. Debette S, Germain DP: Neurologic manifestations of inherited disorders of connective tissue. Handb Clin Neurol 119:565-576, 2014

7. Duthel R, Charret MC, Huppert J, Deluzarches P, Motuo Fotso MJ, Barral F: [Anterior sacral meningocele. Apropos of 11 cases.] Neurochirurgie 34:90-96, 1988 (Fr)

8. Gardner PA, Albright AL: "Like mother, like son:" hereditary anterior sacral meningocele. Case report and review of the literature. J Neurosurg 104 (2 Suppl):138-142, 2006

9. Giordano PA, Griffet J, Argenson C: Pedicled greater omentum transferred to the spine in a case of postoperative infection. Plast Reconstr Surg 93:1508-1511, 1994

10. Hanna AS, Morandi X: Anterior sacral meningocele in pregnancy. Case report. J Neurosurg 94 (1 Suppl):162-164, 2001

11. Heller JG, Kim HS, Carlson GW: Subarachnoid-pleural fistulae-management with a transdiaphragmatic pedicled greater omental flap: report of two cases. Spine (Phila Pa 1976) 26:1809-1813, 2001

12. Kole MJ, Fridley JS, Jea A, Bollo RJ: Currarino syndrome and spinal dysraphism. J Neurosurg Pediatr 13:685-689, 2014

13. Lee KS, Gower DJ, McWhorter JM, Albertson DA: The role of MR imaging in the diagnosis and treatment of anterior sacral meningocele. Report of two cases. J Neurosurg 69:628-631, 1988

14. Loeys BL, Dietz HC, Braverman AC, Callewaert BL, De Backer J, Devereux RB, et al: The revised Ghent nosology for the Marfan syndrome. J Med Genet 47:476-485, 2010

15. Massimi L, Calisti A, Koutzoglou M, Di Rocco C: Giant anterior sacral meningocele and posterior sagittal approach. Childs Nerv Syst 19:722-728, 2003

16. Mesfin A, Ahn NU, Carrino JA, Sponseller PD: Ten-year clinical and imaging follow-up of dural ectasia in adults with Marfan syndrome. Spine J 13:62-67, 2013

17. Mohta A, Das S, Jindal R: Anterior sacral meningocele presenting as constipation. J Pediatr Neurosci 6:40-43, 2011

18. Nallamshetty L, Ahn NU, Ahn UM, Nallamshetty HS, Rose PS, Buchowski JM, et al: Dural ectasia and back pain: review of the literature and case report. J Spinal Disord Tech 15:326-329, 2002

19. Otagiri N, Matsumoto Y, Yoshida Y: Posterior sagittal approach for Currarino syndrome with anterior sacral meningocele: a case report. J Pediatr Surg 35:1112-1114, 2000

20. Peña A, Devries PA: Posterior sagittal anorectoplasty: important technical considerations and new applications. J Pediatr Surg 17:796-811, 1982

21. Raftopoulos C, Pierard GE, Rétif C, Braude P, Brotchi J: Endoscopic cure of a giant sacral meningocele associated with
Marfan's syndrome: case report. Neurosurgery 30:765-768, 1992

22. Sahin N, Genc M, Kasap E, Solak A, Korkut B, Yilmaz E: Anterior sacral meningocele masquerading as an ovarian cyst: a rare clinical presentation associated with Marfan syndrome. Clin Pract 5:752, 2015

23. Sahota S, Nassr A, Khan MH, Marsh RW, Moran SL, Arnold PM, et al: Treatment of a thoracic dural-pleural fistula with a vascularized omental flap: a case report. Spine (Phila Pa 1976) 37:E683-E685, 2012

24. Schneider MB, Dittmar S, Boxer RA: Anterior sacral meningocele presenting as a pelvic/abdominal mass in a patient with Marfan syndrome. J Adolesc Health 14:325-328, 1993

25. Shedid D, Roger E, Benzel E: Presacral meningocele: diagnosis and treatment. Semin Spine Surg 18:161-167, 2006

26. Sheikhzadeh S, Brockstaedt L, Habermann CR, Sondermann C, Bannas P, Mir TS, et al: Dural ectasia in Loeys-Dietz syndrome: comprehensive study of 30 patients with a TGFBR1 or TGFBR2 mutation. Clin Genet 86:545-551, 2014

27. Simpson BA, Glass RE, Mann CV: Anterior sacral meningocoele: magnetic resonance imaging and surgical management. Br J Surg 74:1185, 1987

28. Somuncu S, Aritürk E, Iyigün O, Bernay F, Rizalar R, Günaydin M, et al: A case of anterior sacral meningocele totally excised using the posterior sagittal approach. J Pediatr Surg 32:730-732, 1997

29. Strand RD, Eisenberg HM: Anterior sacral meningocele in association with Marfan's syndrome. Radiology 99:653654,1971

30. Sunna TP, Westwick HJ, Zairi F, Berania I, Shedid D: Successful management of a giant anterior sacral meningocele with an endoscopic cutting stapler: case report. J Neurosurg Spine 24:862-866, 2016

31. Versteegh HP, Feitz WFJ, van Lindert EJ, Marcelis C, de Blaauw I: "This bicycle gives me a headache", a congenital anomaly. BMC Res Notes 6:412, 2013

32. Villarejo F, Scavone C, Blazquez MG, Pascual-Castroviejo I, Perez-Higueras A, Fernandez-Sanchez A, et al: Anterior sacral meningocele: review of the literature. Surg Neurol 19:57-71, 1983

33. Voyvodic F, Scroop R, Sanders RR: Anterior sacral meningocele as a pelvic complication of Marfan syndrome. Aust N Z J Obstet Gynaecol 39:262-265, 1999

\section{Disclosures}

Dr. Levi receives teaching honorarium from the AANS and grant support from the Department of Defense.

\section{Author Contributions}

Conception and design: all authors. Acquisition of data: all authors. Analysis and interpretation of data: all authors. Drafting the article: Levi, Paisan. Critically revising the article: all authors. Reviewed submitted version of manuscript: Levi, Paisan. Approved the final version of the manuscript on behalf of all authors: Levi. Study supervision: Levi.

\section{Correspondence}

Allan D. Levi: University of Miami Miller School of Medicine, Lois Pope LIFE Center, Miami, FL. alevi@med.miami.edu. 